\title{
Could we have prevented all this? A comparison of the British and South Korean primary dental care response to COVID-19
}

\author{
Kowoon Noh, ${ }^{* 1}$ Jasmine Loke ${ }^{1}$ and Kyungmin Kim²
}

\section{Key points}

Outlines why South Korea is viewed as a success case in managing COVID-19 outbreak.
Highlights the difference in the UK and South Korean government and primary dental care responses to the COVID-19 pandemic.
Suggests measures that the dental profession can implement for the future.

\begin{abstract}
To limit the spread of the novel coronavirus (COVID-19), Britain enforced a strict national lockdown, which is affecting the lives of millions, including dental professionals. As a result, all routine dental work has been suspended and general dental practitioners (GDPs) are inevitably faced with financial difficulties, as well as an impending strain on dental services once the lockdown is lifted. In contrast, South Korea (SK) has effectively managed to keep the virus at bay without a lockdown and continues to deliver routine dental care throughout this period. This article compares the current status of primary dental care in the UK and SK under COVID-19, in order to explore how the dental profession can better mitigate the repercussions of a future epidemic crisis.
\end{abstract}

\section{Introduction: why South Korea?}

Following weeks of strict lockdown, the UK appears to have passed the peak of the COVID-19 outbreak, ${ }^{1}$ but a vigilant exit plan is needed to avoid a second wave of infections. Observing the responses of other countries, which had their COVID-19 outbreak peaks before the UK, can assist in formulating such plans. Before the mass outbreak in Europe and the US, South Korea (SK), officially known as the Republic of Korea, had the largest number of confirmed cases of COVID-19, after China. Yet, without imposing a national lockdown, SK achieved a dramatic decline in the number of new cases without a second outbreak peak ${ }^{2}$ and with dental services operating as usual. How is the SK dental service and governance different from the current state in the UK? This article will look into the impact of COVID-19 on the UK's primary dental care, compare this to the situation in SK and suggest measures to

'Dental Core Trainee in Oral and Maxillofacial Surgery; ${ }^{2}$ Specialist Registrar in Clinical Radiology.

${ }^{*}$ Correspondence to: Kowoon Noh

Email address: kowoon.noh@gmail.com

Accepted 8 May 2020

https://doi.org/10.1038/s41415-020-1705-5 maintain the provision of dental care during an epidemic crisis.

\section{COVID-19: impact on UK dental care}

The close face-to-face contact and aerosolgenerating nature of dental procedures mean that dental professionals are a high-risk group in terms of exposure to and transmission of COVID-19. ${ }^{3,4}$ As such, the NHS England Chief Dental Officer announced the suspension of all routine and non-urgent dental care until advised otherwise. ${ }^{5}$ This casued most dental practices to hold remote consultations and act as a triage and advice service in order to guide patients to local urgent dental care centres (UDCs) or to secondary care where appropriate. ${ }^{5}$ The current aim of dental care in the UK is to defer dental treatment for as long as possible. As a result, many patients are only given two treatment options: analgesics and/or antibiotics. ${ }^{5}$

The dental profession's main concern throughout this crisis has always been patient safety. Delays in seeking dental treatment can lead to infectious spread, leaving patients with suboptimal or irreversible treatment options. Other concerns are the compromised dental care given to patients who are mid-treatment with temporary measures, and the delayed diagnoses of dental diseases or malignancy due to the cessation of routine check-ups. With compromised care quality, future dental litigation claims related to COVID-19 are a realistic possibility.

COVID-19 has also burdened the general dental practitioners (GDPs). In the initial phase of the outbreak, dental professionals not only had to worry about the effect of limited provision of dental treatment on patient care, but also the possibility that they could be contracting and transmitting COVID-19 to and from patients. With the cessation of routine dental care, introduction of national personal protective equipment (PPE) guidelines and prioritised distribution of PPE to UDCs, ${ }^{6,7}$ the fear of COVID-19 transmission through dental work has lessened. However, if routine dental work were to be resumed, the government would likely have to take on the additional responsibility of maintaining adequate and constant supplies for primary dental practices as well.

Furthermore, the financial impact of COVID-19 on dentistry cannot be overlooked, since many dental practices have been forced to close for more than a month. The majority of dentists in primary care are self-employed, which makes them financially more vulnerable than the NHS-employed medical colleagues. 
Although the government promised supportive schemes and continuation of NHS contract payments, mixed practices and private practices will receive less support. ${ }^{8}$ This causes uncertainty regarding individual practice development plans and the future of employment in the sector.

\section{COVID-19: SK government response and dental care}

SK has shown that it is possible to contain the virus without imposing a stringent lockdown or a blanket ban on people coming from China. Routine dental services in SK have continued with minimal interruption during this period. How has SK tackled the COVID-19 outbreak?

SK confirmed its first COVID-19 case in late January 2020, ${ }^{2}$ ten days before the first diagnosed case in the UK. ${ }^{1}$ In February, SK experienced an exponential spike in COVID-19 cases following the emergence of a 'super-spreader' from a reclusive church. ${ }^{2}$ Within a few weeks, SK became the country with the highest number of COVID-19 cases outside of China. However, in less than a month since its mass outbreak, the number of recovered patients outweighed the number of active cases. ${ }^{2}$ SK recently relaxed its social distancing rules, as its number of new cases remains low despite even holding a general election during the crisis. ${ }^{9}$

\section{Government strategy}

SK's strategy in limiting COVID-19 spread could be summarised as mass testing, followed by meticulous contact tracing and a strictly enforced quarantine of individuals who came into close contact with confirmed cases. ${ }^{10}$ The SK system has enabled early admission of positive patients to specified COVID-19 hospitals or Community Treatment Centres, ${ }^{10}$ and as a result, protected the rest of the population. This also enabled the general public to seek dental treatment safely when needed. The SK government has linked the public's travel history system to a prescription safety check programme that is installed in every healthcare practice in SK..$^{10}$ This permits dental practices to access patients' recent travel history and receive live updates on confirmed cases or close contacts of confirmed cases.

\section{Dentistry response}

The Korean Dental Association (KDA) stated that it is not within their authority to ban dental practices from seeing patients, but the duty of patients' GDPs to risk-assess individuals' conditions and to advise whether to delay or continue dental treatment during the pandemic. ${ }^{11}$ SK healthcare professionals, including dentists, have paid particular attention to infection control in the clinical setting since the outbreak of Middle East Respiratory Syndrome (MERS) in 2015. ${ }^{12}$ A Daejeon-based primary care orthodontist, Dr Park, said: 'It is very common for dental practices to install thermal imaging cameras, and have an isolated room for measuring the temperatures of staff/patients. ${ }^{13}$

\section{PPE usage and supply}

As per World Health Organisation (WHO) guidelines, ${ }^{14} \mathrm{SK}$ dentists in primary care are using KF94 respirators (N95/FFP2 equivalent), with a face shield or with goggles where an aerosol generating procedure (AGP) is required. ${ }^{11}$ However, many dentists also wear KF94 in non-AGPs. ${ }^{11}$ The probability of SK dentists performing an AGP on a suspected or asymptomatic patient is relatively low due to the country's mass testing and tracing network; any suspected patients with urgent dental needs are directed to secondary/tertiary care. To tackle PPE shortage in dental care, provision of PPE has been prioritised and unified, from the Public Procurement Service directly to the KDA for allocation to individual practices. ${ }^{15}$

\section{Financial support}

The public's avoidance of healthcare settings, due to fear of contracting COVID-19, and the SK government's call for social distancing alarmed the dental community. Some practices have altered their working hours and some have considered a temporary shutdown. In response to this, the SK government has simplified the financial support application procedure and raised the allowance for its business support scheme. ${ }^{16}$ Dental practices can apply for funding for six months when faced with temporary closures and for funding up to a year in case of reduced working hours. ${ }^{16}$ With the recent phased easing of social distancing policies, dental care in Korea will likely slowly return to pre-COVID-19 patient numbers.

\section{What can we adapt in the UK?}

The reason many SK dentists could remain on duty during this global crisis is strongly related to the nation's early response and aggressive mitigation efforts against COVID-19. The lockdown in the UK will eventually come to an end, but many dentists are worried it will take considerable time for them to return to a safe working environment. We appreciate that SK and the UK are currently in different phases of the pandemic. Nevertheless, important lessons can be learned from countries that have faced the virus before us. The following suggestions are to be considered in preparation for the near and distant future.

\section{Prevent a second wave at all costs}

In hindsight, earlier and stricter social distancing when cases were rising in other European countries, widespread testing and active use of contact tracing could have prevented the grave social and economic consequences in the UK. We have now passed the outbreak peak, but a second wave of COVID-19 is possible as soon as the lockdown is lifted, as seen in Singapore and Japan. ${ }^{17}$ To prevent this, we must attempt to incorporate SK's strategies of strict social distancing rules, testing of all asymptomatic/ mildly symptomatic individuals and rigorous contact tracing.

\section{Implement a long-term stage response plan}

Mr Kwon, chief of the Korean Centre for Disease Control and Prevention (KCDC), announced: 'The world before COVID-19 will never return. We have to prepare for the new norm. ${ }^{18}$ Until a vaccine against COVID-19 becomes available, our daily life must continue to focus on prevention and social distancing. Experts report the COVID-19 pandemic could last up to two years. ${ }^{19}$ The diversion and redeployment of GDPs, and the establishment of UDCs, are viable, but are only short-term approaches to relieve the demand on the NHS. Measures against COVID-19 should not be an urgent manoeuvre, but a transformation of the entire system into a sustainable model that allows patient access to routine dental care. To achieve this, response from authorities may include: distributing PPE to all dental practices across the nation; aiding practices in the designation of a safe patient waiting area; and environmental cleaning guidelines. Other guidance may include: appropriate usage of PPE according to the phases of the pandemic (including post-peak and post-pandemic); staff training in the correct gowning/de-gowning of PPE; and health and travel history screening for patients and staff. When faced with highest levels of community spread, routine dental care may still be suspended, but at least this could be staged. Having a pre-determined stage response plan will take away significant uncertainty and anxiety for professionals and patients alike. 


\section{Self-assess your practice}

Dr Kim, a dental practice owner in Seoul, said this would not be the last pandemic, as 'novel viruses will continue to emerge, and healthcare will continue to develop accordingly. ${ }^{20}$ Following the MERS outbreak, some dental practices in SK went through a major renovation to allow adequate ventilation of the surgery. ${ }^{20}$ Their actions are based on the research reporting a significant reduction in the risk of pathogens when appropriate disinfection and ventilation have taken place $(<1 \%$ airborne contamination remains after five air changes). ${ }^{21}$ It is good practice for practice managers to revise their policy on remote consultation, staff training in infection control measures and decontamination of high-touch areas (for example, door handles and lift buttons). Staff management policies can be considered, such as staggering patient appointments and arranging separate dental teams to come into work each day.

\section{Utilise advanced technology}

SK's use of surveillance technology and tracking of mobile phone and bank card usage to trace the footsteps of the virus has been crucial to determine whom to test or isolate, thus protecting the public. ${ }^{2}$ Although this may not be readily applicable to many other countries due to ethical and technical concerns, we should perhaps contemplate some form of national digital health information system, including a nationwide electronic case notification system, when so much is at stake. This may prompt further guidelines regarding data protection. Nonetheless, mandatory use of mobile phone apps during self-isolation will allow authorities to monitor patients' location and daily symptoms, and to enforce self-isolation to prevent suspected COVID-19 patients from attending primary healthcare facilities, even after the lockdown. Other apps or websites incorporating the GPS technology will also be able to guide patients promptly to the nearest local UDC.

\section{Build contingency plans for future pandemics}

Like SK, which adapted new healthcare regulations and protocols after the MERS outbreak in 2015, the UK should consider evolving its public health system by revising regulations for the future. On top of researching vaccinations, the government should actively support the development of dental healthcare with regards to future pandemic outbreaks, including the funding of research on clinical microbiology, and the revision of regulations regarding the stocking and supplying of highperformance respirators as part of emergency kits in practices across the nation. We should perform an appraisal on UDCs to determine whether establishing them would still be the best course of action for different stages of a pandemic. In a broader context, this will also include revising legislation to promote self-sustainable recovery of small businesses instead of depending on loans, should similar situations happen again.

\section{Promote public adherence and hygiene}

SK's tackling strategy against COVID-19 was primarily 'prevention via thorough hygiene, rather than the UK's initial 'herd immunity' approach. In this new era, patients must be meticulous with personal hygiene and be mindful of etiquette when attending routine dental appointments; for example, delaying these where possible if they/ their household member(s) have mild COVIDlike symptoms. Although a controversial topic, there has been an increase in evidence supporting universal masking. ${ }^{22}$ Greenhalgh's article in the BMJ states that 'masks could have a substantial impact on transmission with a relatively small impact on social and economic life, as evidenced in SK, Hong Kong and Japan. ${ }^{17}$ Can our society afford to wait for randomised controlled trials before recommending a simple and potentially effective strategy adopted with apparent success elsewhere?

\section{Conclusion}

COVID-19 is unlikely to be the last global virus outbreak in our lifetime. Cessation of routine dental care every time the nation faces a novel threatening virus will result in unfavourable cascade effects with regards to patient care, dental businesses, education and training, and secondary public health services. However, with every challenge, there is an opportunity. Now is the time to review the existing limitations of our response and revise for the future. Equally, it is the responsibility of the authorities to assist individual professions to work safely within their scope of practice. Our healthcare and dental community must learn important lessons from today to become more resilient to future infectious crises.

\section{References}

1. UK Government. Coronavirus (COVID-19) cases in the UK. 2020. Available at https://coronavirus.data.gov.uk (accessed April 2020).

2. Minister of Health and Welfare K. Coronavirus Disease-19, Republic of Korea. 2020. Available at http:// ncov.mohw.go.kr/ (accessed April 2020).
3. Coulthard P. Dentistry and coronavirus (COVID-19) - moral decision-making. Br Dent J 2020; 228: 503-505.

4. Peng X, Xu X, Li Y, Cheng L, Zhou X, Ren B. Transmission routes of 2019-nCoV and controls in dental practice. Int J Oral Sci 2020; 12: 9.

5. NHS England and NHS Improvement. COVID-19 guidance and standard operating procedure: Urgent dental care systems in the context of coronavirus. 2020. Available at https://www.england.nhs.uk/coronavirus/wp-content/ uploads/sites/52/2020/04/C0282-covid-19-urgent-dentalcare-sop.pdf (accessed April 2020).

6. Public Health England. COVID-19: personal protective equipment (PPE). 2020. Available at https://www.gov. uk/government/publications/wuhan-novel-coronavirus infection-prevention-and-control/covid-19-personalprotective-equipment-ppe (accessed May 2020).

7. Public Health England. COVID-19: infection prevention and control (IPC). 2020. Available online at https:// www.gov.uk/government/publications/wuhan-novelcoronavirus-infection-prevention-and-control (accessed May 2020).

8. British Dental Association. Coronavirus: the financial impact. 2020. Available at https://bda.org/advice/ Coronavirus/Pages/financial-impact.aspx (accessed May 2020).

9. Cha S. South Korea relaxes some social distancing rules as new virus cases fall. Reuters (London) 2020 April 19.

10. Ministry of Health and Welfare C. COVID-19 Response: Korean Government's Response System. 2020. Available at http://ncov.mohw.go.kr/en/baroView.do?brdld= $11 \&$ brdGubun $=111 \&$ dataGubun $=\&$ ncv ContSeq $=$ \&contSeq=\&board_id (accessed April 2020).

11. Korean Dental Association. COVID-19: Advice to dental profession. 2020. Available online at https://www.kda. or.kr/ (accessed April 2020).

12. Cho H. Effectiveness for the Response to COVID-19: The MERS Outbreak Containment Procedures. Osong Public Health Res Perspect 2020; 11: 1-2.

13. Park K. The impact of COVID-19 in South Korean dental practice (online interview). 26th March 2020..

14. WHO. Rational use of personal protective equipment for coronavirus disease (COVID-19) and considerations during severe shortages. 2020. Available online at https://www. who.int/publications-detail/rational-use-of-personalprotective-equipment-for-coronavirus-disease-(covid-19)and-considerations-during-severe-shortages (accessed May 2020).

15. Central Disaster Management Headquarters. Unification of mask provision to all medical institutions. 2020. Available at http://ncov.mohw.go.kr/tcmBoardView. do? brdld $=\&$ brdGubun $=\&$ dataGubun $=\&$ ncvContSeq $=$ 353384\&contSeq=353384\&board_id=140\&gubun=BDJ (accessed May 2020).

16. Ministry of Employment and Labor. Government will simplify procedures for subsidy for flexible work arrangements to fight against COVID-19. 2020. Available at https://www.moel.go.kr/english/poli/poliNewsnews_ view.jsp?idx=1555 (accessed March 2020).

17. Greenhalgh T, Schmid M, Czypionka T, Bassler D, Gruer L. Face masks for the public during the covid-19 crisis. BMJ 2020; DOI: 10.1136/bmj.m1435.

18. Korea Centres for Disease Control and Prevention. The updates on COVID-19 in Korea as of 11 April. 2020. Available online at https://www.cdc.go.kr/board/board. es? $\mathrm{mid}=\mathrm{a} 30402000000 \&$ bid $=0030$ (accessed May 2020).

19. Moore K A, Lipsitch M, Barry J M, Osterholm M T. COVID-19: The CIDRAP Viewpoint. 2020. Available at https://www.cidrap.umn.edu/sites/default/files/ public/downloads/cidrapcovid19viewpoint-part1_0.pdf (accessed May 2020)

20. Dental Arirang. Special interview: Seoul Sha Dental Practice Dr Kim. 2020. Available at https://www. dentalarirang.com/news/articleView.html?idxno=28121 (accessed May 2020).

21. Cheong C, Park B, Lee S. Design Method to Prevent Airborne Infection in an Emergency Department. J Asian Archit Build Engin 2018; 17: 573-579.

22. Esposito S, Principi N, Leung C, Migliori G. Universal use of face masks for success against COVID-19: evidence and implications for prevention policies. Eur Respir J 2020; DOI: 10.1183/13993003.01260-2020. 